\title{
Design and Characterization of a Horizontal Double Impinging Jet Cell: Determination of Flow Modes at the Surface of a Flat Electrode
}

\author{
Désiré M. K. Abro', Pierre Dable², Fernando Cortez-Salazar³, Véronique Amstutz ${ }^{3}$, \\ Edith Kouassi Kwa-Koffi ${ }^{1}$, Hubert Girault ${ }^{3}$ \\ ${ }^{1}$ Laboratoire de Chimie Physique, Université Félix Houphouet-Boigny, Abidjan, Côte d'Ivoire \\ ${ }^{2}$ Laboratoire de Thermodynamique de Traitement et Sciences des Surfaces et Interfaces, Institut National \\ Polytechnique Félix Houphouet-Boigny, Yamoussoukro, Côte d'ivoire \\ ${ }^{3}$ Laboratoire d'Electrochimie Physique et Analytique, Ecole Polytechnique Fédérale de Lausanne, Sion, Suisse \\ Email: abrodesire@hotmail.com
}

Received 25 July 2016; accepted 23 August 2016; published 26 August 2016

Copyright (C) 2016 by authors and Scientific Research Publishing Inc.

This work is licensed under the Creative Commons Attribution International License (CC BY). http://creativecommons.org/licenses/by/4.0/

\section{(c) (i) Open Access}

\begin{abstract}
An electrochemical cell consisting of a double horizontal Impinging Jet Cell (IJC) has been conceived and characterized. The purpose of this system is the simultaneous electrodeposition of a composite metal/particle coating on both surfaces of a metal sheet. The silica particles imprint in the nickel matrix has allowed to distinguish four different flow areas onto the electrode namely the stagnation area, the radial flow area characterized by a higher flow speed, the return flow area that involves gravity effect, and the drainage area with a constant draining speed. Based on the limiting current evolution as a function of the Reynolds number, three flow modes were extracted: the Laminar Low Flow (LLF), the Laminar High Flow (LHF) and the Disturbance. The IJC investigated ensures a laminar flow for a large range of flow rate from a nozzle-to-sample distance of 19 mm and creates an laminar flow ovoid plan merged with the sample for the high flows.
\end{abstract}

\section{Keywords}

Impinging Jet Cell, Hydrodynamic, Flow Regimes, Electrocodeposition

\section{Introduction}

Particles embedment into metal matrix by electrocodeposition is increasingly used to improve mechanical properties, corrosion resistance [1]-[5] and lubrication [6]. For its practical implementation and its relatively low cost, this process is a serious option for industrial applications. Many papers have reported ways to increase the par- 
ticles amounts into coatings. These studies show that particles incorporation depends on their load in the deposition bath, the physical chemistry associated to their particle surface state [7], and hydrodynamics during the coating process [8]-[10]. Keeping adequate hydrodynamic characteristics allows to maintain the particles in suspension and to carry them to the cathode surface for their entrapment in the growing metal matrix. In practice, the hydrodynamic behavior of the fluid is controlled by magnetic stirring or by impinging cell jet [11]. In a classical electrochemical cell, magnetic stirring improves the particle codeposition until a certain limit [12], [13]. Nevertheless, the architecture of this kind of cell does not lead to a quantitative relationship between rotation speed and mass transport parameters. Then, the development of an electrocodeposition process enabling the control of homogeneity and technical monitoring of deposits becomes essential. In this perspective, IJCs appear to be a more suitable alternative. Indeed, in this system, the electrolyte is propelled in the form of a jet, which is impinging perpendicularly to the cathode. As a consequence, the mass transport is improved. The mass transfer coefficient can be assessed as a function of the liquid velocity or more precisely as a function of the Reynolds number. In fact, Chin et al. [14] discussed a relationship between the limiting current and the Reynolds number. Using an IJC impinging jet cell, Osborne and coworkers [15] successfully embedded $3 \mathrm{wt} \%$ of $50 \mathrm{~nm} \gamma-\mathrm{Al}_{2} \mathrm{O}_{3}$ in electrodeposited copper by varying the flow rate from 1 to $7 \mathrm{~L} / \mathrm{min}$. Also, Dablé et al. [9] achieved to introduce a mass of about $85 \%$ of silicon carbide into a nickel matrix by applying a turbulent flow.

Previous works have focused on the characterization of a vertical impinging jet cell [9], [15], [16]. However, for an industrial application this orientation is not optimal as it allows the processing of only one side of the substrate at a time. Such a process would lead to a loss of time as well as a more complicated handling. The advantage of a method allowing the simultaneous treatment of both sides of a specimen is therefore paramount. A cell with two horizontal jets reaching the two surfaces of the substrate sample becomes an attractive option. To this end, such an electrochemical IJC has been designed in this study. The flow characteristics at the surface of the specimens have also been characterized.

\section{Materials and Methods}

\subsection{The Horizontal Impinging Jet Cell}

The cell designed for this study consists of two parts. The body of the cell is a glass cylinder of $70 \mathrm{~mm}$ diameter and a height of $45 \mathrm{~mm}$ (Figure 1(a)). Two pairs of $6 \mathrm{~mm}$ holes were drilled, facing each other two by two, at

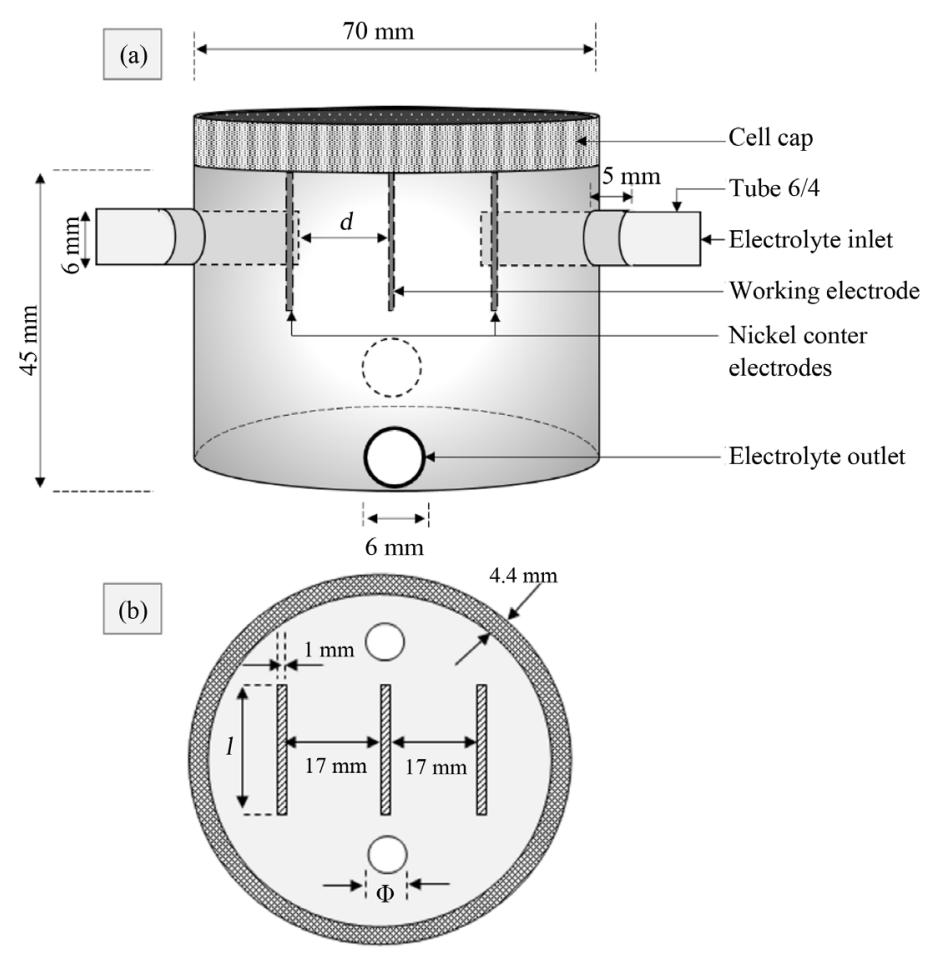

Figure 1. Schemes of the body (a) and of the cap (b) of the IJC. 
two different heights, and each pair was placed at $90^{\circ}$ from each other. The two upper holes, in which tubes with an internal diameter of $4 \mathrm{~mm}$ are introduced, guide the electrolyte stream towards the working electrode (electrolyte inlet) on the two faces of the substrate. The excess of electrolyte is evacuated through the lower holes pair. The flow rate, ensuring a proper agitation of the electrolyte, is controlled by a peristaltic pump. The internal volume of the cell is $150 \mathrm{~cm}^{3}$. The cap (Figure 1(b)) of the cell is made of Teflon and fits with the glass body. Two holes with a diameter $\Phi$ equal to $5 \mathrm{~mm}$ were pierced for the reference electrode and the degassing of hydrogen that could be produced during the electrochemical process. Three slits of $10 \mathrm{~mm}$ length separated by $17 \mathrm{~mm}$ were added in order to arrange the electrodes.

The working electrode stands in the middle and two counter electrodes are placed on each side equidistantly with the working one. Such a positioning allows a simultaneous treatment of both surfaces of the working electrode and insures a homogeneous distribution of the electrical field lines, at the same distance to the cathode with the flow jet. It also enables the investigation of the effect of the distance $d$ between the nozzle and the working electrode on the flow mode.

The complete system of the jet cell and the peristaltic pump (Isamatec) is shown in Figure 2(a).

The working electrode and the two counter-electrodes were made of a pure nickel foil (Alfa Aeser) of $1 \mathrm{~mm}$ thick cut in a T-shape according to the dimensions indicated in Figure 2(b). This shape allowed the insertion of the electrodes into the slits of the cap. Their upper parts of $5 \mathrm{~mm}$ remaining on top of the cap have served for the electrical connection. In the middle of each counter electrode, a hole of $6 \mathrm{~mm}$ in diameter was made to introduce the jet nozzles in PVC. These PVC tubes were slipped through the openings until reaching a nozzle-to-cathode distances of 5, 10 and $15 \mathrm{~mm}$ for guiding the impinging liquid jet.

\subsection{Hydrodynamic Considerations and Flow Regimes Determination}

The mass transfer coefficient $K$ associated to the working electrode limiting current $i_{\lim }$ of the process is expressed as [17]:

$$
K=i_{\lim } /(n F C)
$$

where $n$ is the number of electrons exchanged in the electrochemical process, $F$ is the Faraday constant and $C$ the concentration in electro-active species.

The Sherwood number $S h$, which represents the ratio between the total mass transfer and diffusion transfer to the surface of an electrode is expressed by:

$$
S h=\left(i_{\lim } R\right) /(n F C D)
$$

where $R$ is the radius of the surface of the electrode and $D$ is the diffusion coefficient.

The Reynolds number Re, which represents the significance inertial forces associated with the flow rate in contrast to the kinematic viscosity strength and allows distinguishing the limits of flow regimes is established by:

$$
\operatorname{Re}=\left(V d_{0}\right) / v
$$

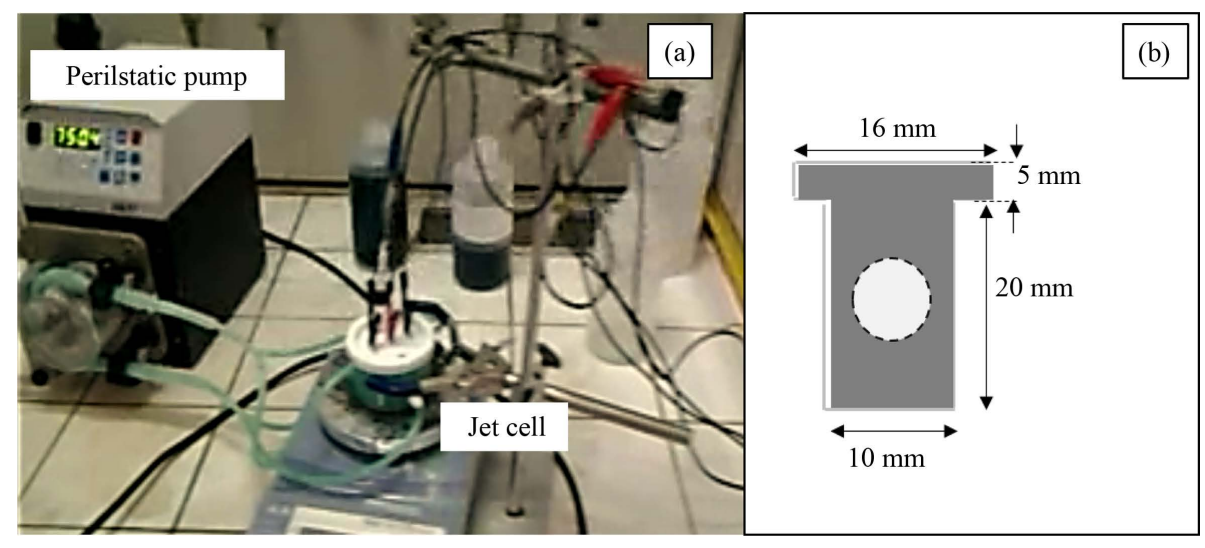

Figure 2. Optical image of the cell jet system (a). Working and Counter electrodes shape and dimensions (b). 
With $V$ being the flow velocity in $\mathrm{cm} / \mathrm{s}, v$ the kinematic viscosity in $\mathrm{cm}^{2} /$ secand $d_{0}$ the nozzle diameter in $\mathrm{cm}$. In the case of this work where the liquid is not subjected to heat transfer, the Sherwood number is expressed as:

$$
S h=a S c^{\frac{1}{3}} \operatorname{Re}^{\frac{1}{2}}
$$

With $a$ being the hydrodynamic coefficient characterizing the flow, and $S c$ the Schmidt number which is the ratio of the kinematic viscosity $v$ and the diffusion coefficient $D$.

From Equation (2) and Equation (4), one establishes the relationship between the limiting current and the Reynolds number as follow:

$$
i_{\lim }=\left(\left(\operatorname{anFCDSc^{\frac {1}{3}}}\right) / R\right) \operatorname{Re}^{\frac{1}{2}}
$$

The terms constituting the current variation coefficient versus the square root of Re are all constants except the hydrodynamic coefficient $a$. Thus, any change of slope will reflect a flow regime change. In the current study, an equimolar solution of potassium ferri- and ferrocyanide of $5 \mathrm{mM}$ ions in an aqueous solution of potassium hydroxide $100 \mathrm{mM}$ has served as electrolyte for characterizing the flow conditions in the IJC.

For each flow rate in $\mathrm{cm}^{3} / \mathrm{s}$, the flow velocity $V$ was determined based on the following dimensions and parameter values: $R=0.2 \mathrm{~cm}, n=1, F=96500 \mathrm{C}, D=7.9 \times 10^{-6} \mathrm{~cm}^{2} / \mathrm{sec}$, and $S C=1215$. The kinematic viscosity of the electrolyte $v$ was determined to be $0.99 \mathrm{~mm}^{2} / \mathrm{s}$ using a viscometer (Viscometer sv-1a).

For different flow rates, the corresponding Reynolds numbers was calculated by Equation (3), and the limiting currents for reduction and oxidation processes were measured with the technique of linear sweep voltammetry, where voltammograms were recorded using a galvanostat-potentiostat (Autolab PGSTAT302N, Metrohm). The reference electrode was an $\mathrm{Ag} / \mathrm{AgCl}$ in saturated $\mathrm{KCl}$ solution.

\subsection{Flow Description}

To describe the flow on the working electrode surface, its imprint was collected during the codeposition of a nickel/silica composite coating performed at room temperature. The composition of the Watt type suspension used for this process is provided in Table 1.

The size of silica particles (Sikron-B600) is in a range of 1 to10 $\mu \mathrm{m}$.

The different flow areas and the flow profile have been visualized through the silica particles distribution in the nickel matrix examined by scanning electron microscopy SEM (Philips XLF-30 FEG).

\section{Results and Discussions}

\subsection{Characterization of the Flow at the Sample Surface}

In Figure 3, the black spots, corresponding to the silica particles codeposited with nickel impressively depict the liquid jet on the cathode.

In view of the particles distribution, the overall shape of the imprint may be set together with the history of their movement. Four areas, here called A, B, C and D of the jet flow at the electrode surface are characterized by different flow rates:

Area A: This area is the impact zone. It presents a high amount of particle encrusted. The particles in the

Table 1. Watt bath composition for nickel-silica composite electrodeposition.

\begin{tabular}{cc}
\hline Chemicals & Concentration $\left(\mathrm{g} \cdot \mathrm{L}^{-1}\right)$ \\
\hline $\mathrm{NiSO}_{4} ; 7 \mathrm{H}_{2} \mathrm{O}$ & 250 \\
$\mathrm{NiCl}_{2} ; 6 \mathrm{H}_{2} \mathrm{O}$ & 90 \\
$\mathrm{H}_{3} \mathrm{BO}_{3}$ & 30 \\
Sodium dodecylsulfate (SDS) & 0.14 \\
$\mathrm{SiO}_{2}$ particles & 30 \\
\hline
\end{tabular}



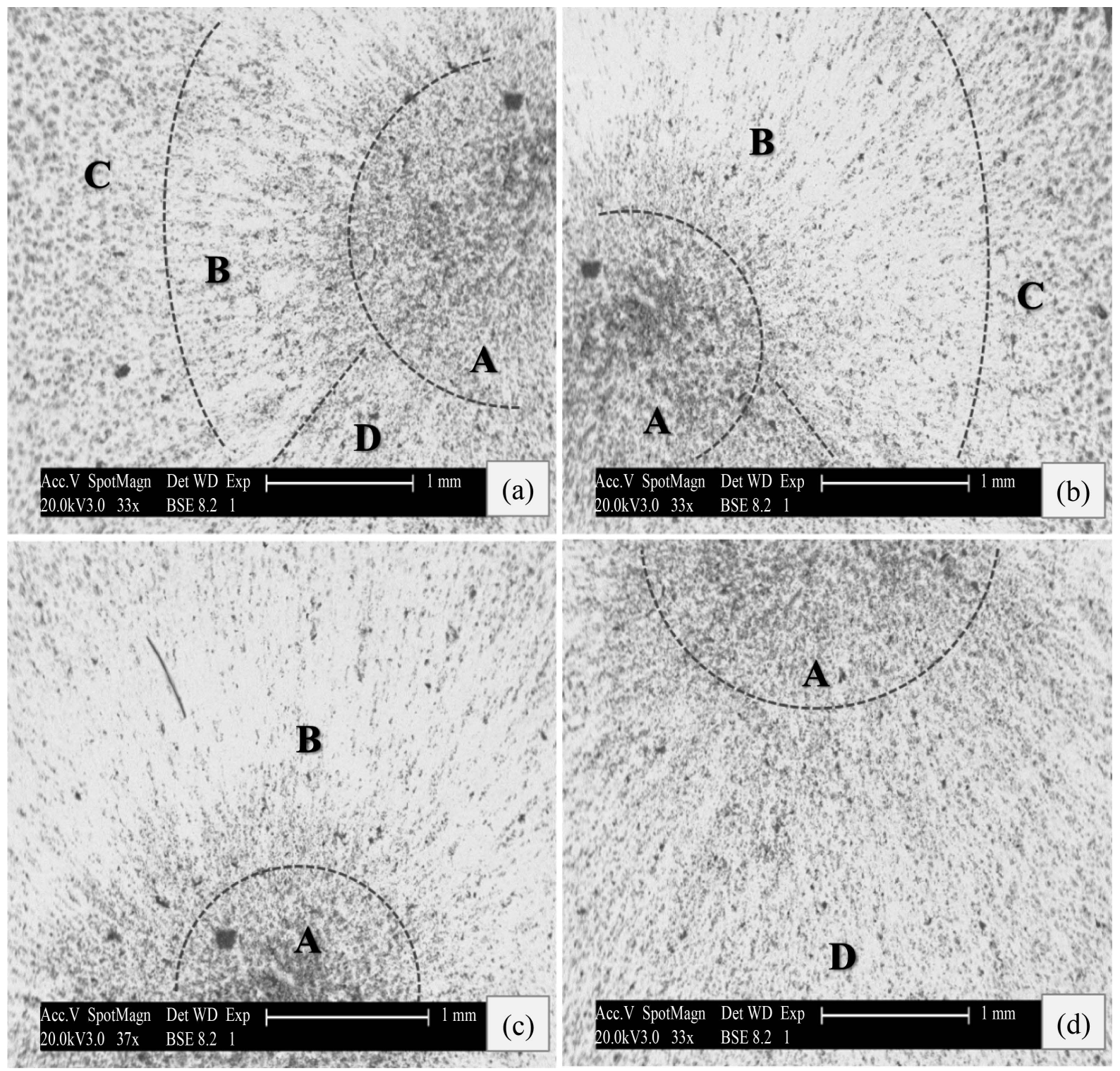

Figure 3. SEM image of the structure of the jet after electrodeposition of the composite $\mathrm{Ni}^{-\mathrm{SiO}_{2}}$ (a) Left side; (b) Right side and, (c) and (d) Superior and Lower side of the flow. $E=-0.9 \mathrm{~V} ; \boldsymbol{d}=5 \mathrm{~mm}$.

electrolyte support the same force and, the residence time over this area is being longer, the probability of embedment is necessarily more important. Area A corresponds to the stagnation zone.

This system proceeds as a spray coating. A major advantage of such system is the possibility to coat a given surface with a predicted particle amount into the metal matrix.

Area B: In accordance with particles imprint, this area characterizes the radial flow of the liquid after impacting the working electrode. The upper part formed above area A looks like a crescent moon with a weak rate of embedded particles. In fact, particles move away from the working electrode carried by the liquid back motion or by elastic shocks. The spacing between the flow lines increases betraying an increasing radial velocity $\vec{V}_{r}$. The spreading of the radial flow area is larger in the vertical upward position than in the bottom where it narrows. The lateral width of this zone is estimable to be $1.8 \mathrm{~mm}$ when $d$ is of $5 \mathrm{~mm}$.

Area C: It concerns the return of the suspension after the impact and the radial flow. In this area, the distribution of particles is intense and homogeneous due to an extended living time of the particles in the layers which have their speed annihilated at the surface of the electrode. Indeed, under the effect of weightlessness, the radial velocity of the liquid suddenly annihilates. This forms a thick layer of solution at the surface of the substrate that 
flows down around the radial flow area B.

Area D: After impact, the liquid layers in the lower plan normally flow down under the effect of gravity. To these waves, those flowing back from area $\mathrm{C}$ are added. Then, these homogeneous layers formed, drains particles with a constant drainage speed $\overrightarrow{V_{d r}}$ along the median surface of the specimen under the peristaltic pump aspiration. The probability of particles embedment increases due to the sum of flux that joined in this area as established in Figure 3.

In the light of this description, the flow profile at the working electrode surface can be sketched as presented in Figure 4.

\subsection{Flow Regimes Characterization by Electrochemical Measurement}

The limiting currents of oxidation and reduction plotted as a function of the square root of corresponding Reynolds number for $d$ equal to 5, 10 and $15 \mathrm{~mm}$ are presented in Figure 5 .

All graphs present the same shape irrespectively of the electrochemical process considered and the nozzle-to-sample distances investigated. Three flow regions denoted I, II and III stand out. The limiting current evolution is characterized by a linear increase in regions I and III interrupted by a plateau in region II.

The slopes of regions I and III exhibit the same value as summarized in Table 2.

This indicates that the flow regime is the same in both regions I and III. Low flow velocities conditions in region I are related to a laminar flow. Since the hydrodynamic coefficients remain identical for the higher flow velocities in region III, it is conceivable that the flow in these conditions also remains laminar. Moreover, the liquid renewal in the system occurs by the peristaltic aspiration and not by overflowing. This particularity results from the cell configuration. Indeed, the electrolyte that reaches both faces of the sample is sucked by the peristaltic pump from the bottom, ensuring a wave regulation: The waves are absorbed, stabilizing the flow and maintaining it laminar. The flow lines are not disturbed and do not create turbulences as commonly observed [16], [18]. Hydrodynamic layers are so kept. Then, the region I will be defined here as the region of laminar low flow (LLF) regime and the region III as laminar high flow (LHF) regime. Then, the plateau of the region II cannot be interpreted as a transition but instead as a disturbance of the impinging jet by the return of flow as previously characterized in area $\mathrm{C}$. The disturbance is initiated at $\mathrm{Re}=3845$ for $5 \mathrm{~mm}$ between the sample and the nozzle, while it only starts at $\mathrm{Re}=3970$ for a distance of $15 \mathrm{~mm}$. This reflects that for a longer distance, a higher flow rate is necessary for the return flows to destabilize the jet. Likewise, the plateau disappears for lower Reynolds numbers as $d$ increases. This indicates that this disturbance is directly related to the energy of the impact. In fact, at a distance of $15 \mathrm{~mm}$, the jet impact energy is the lowest studied. Most important flows as well as

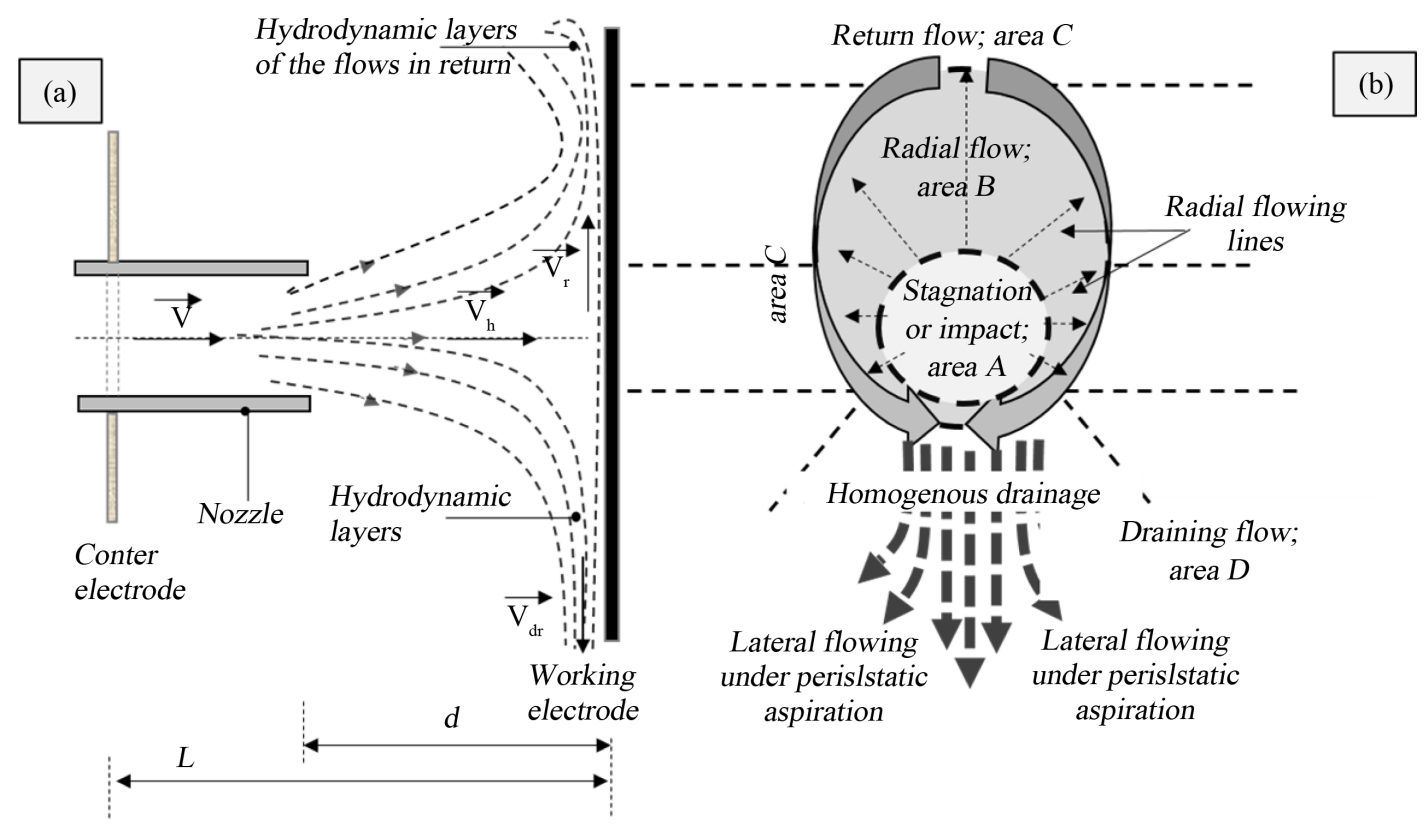

Figure 4. Scheme describing the flow characteristics areas; (a) profile and (b) front view. 

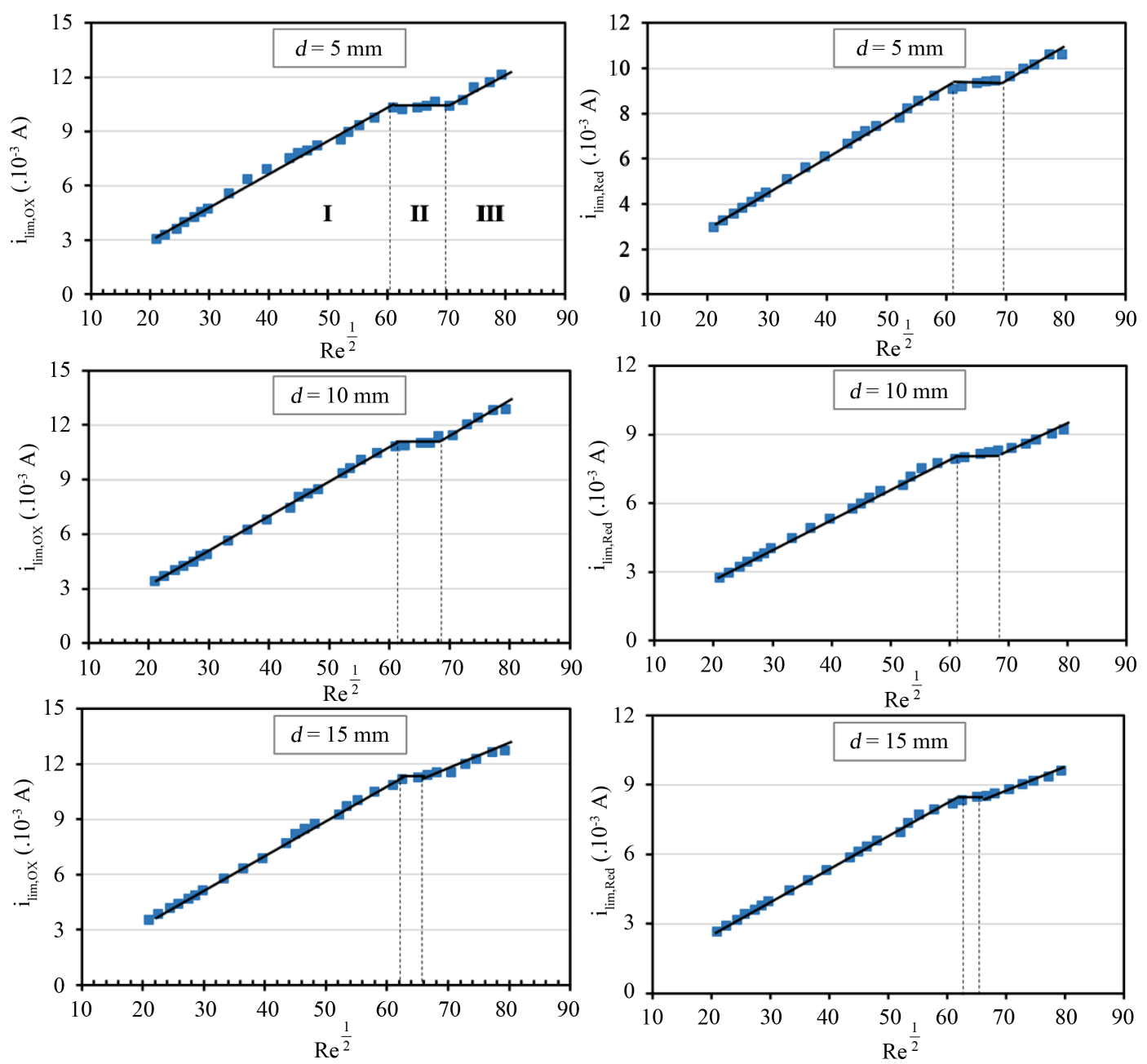

Figure 5. Evolution of oxidation of ferrocyanide (left) and reduction of ferricyanide (right) limiting current of as a function of the square root of the Reynolds number for nozzle-to-sample distancesd = 5, 10 and $15 \mathrm{~mm}$.

Table 2. Table type values of the slopes of the limiting current of the oxidation and reduction processes as a function of the square root of Re and for different values of $d$.

\begin{tabular}{|c|c|c|c|c|c|c|c|}
\hline & & \multicolumn{6}{|c|}{$d$} \\
\hline & & \multicolumn{3}{|c|}{ Oxidation } & \multicolumn{3}{|c|}{ Reduction } \\
\hline & & $5 \mathrm{~mm}$ & $10 \mathrm{~mm}$ & $15 \mathrm{~mm}$ & $5 \mathrm{~mm}$ & $10 \mathrm{~mm}$ & $15 \mathrm{~mm}$ \\
\hline \multirow{3}{*}{ Regions } & I & 0.88 & 0.88 & 0.84 & 0.79 & 0.69 & 0.69 \\
\hline & II & 0 & 0 & 0 & 0 & 0 & 0 \\
\hline & III & 0.88 & 0.88 & 0.84 & 0.79 & 0.69 & 0.69 \\
\hline
\end{tabular}

higher Reynolds numbers are necessary for the return flows to disturb the incident jet. At theses Reynolds numbers, the incident jet with a horizontal velocity $\vec{V}_{h}$ is disturbed by the return of significantly higher speed flows. Since the active surface of the cathode does not change, an increase of the limiting current is necessarily due to convection. Then, the disruption of the jet by the return flows impedes the convection of electroactive species towards the working electrode and the limiting current stabilizes at a constant value. But in proportion as the flow increases, the disturbance is overcome and the current rises again.Nevertheless, for higher nozzle-to-sample distances, the extent $\Delta \mathrm{Re}^{1 / 2}$ defining the plateau of the region II decreases. This extent remains identical for 
both the reduction and oxidation processes for a given $d$. For example, $\Delta \operatorname{Re}^{1 / 2}$ is 9.59 for $d$ equal to $5 \mathrm{~mm}$. But the length of the plateau decreases as $d$ increases suggesting his disappearance for higher values of $d$. In fact, as depicted in Figure 6, $\Delta \mathrm{Re}^{1 / 2}$ is an affine function of $d$, and the plateau might disappear at around $19 \mathrm{~mm}$.

This result indicates that the IJC allows keeping a laminar flow on a working electrode whatever the Reynolds number as from $19 \mathrm{~mm}$. The designed cell is so suitable to improve the uniformity of composite coatings and for electroplating spray applications.

\subsection{Evolution of the Diffusion Layer Thickness}

The voltammograms presented in Figure 7, showed that the current response change depending on Reynolds numbers.The peaks current of reduction and oxidation disappear in favor of a plateau for high Reynolds numbers indicating the contraction of the diffusion layer, especially in area A, the stagnation zone.

After the impact, the fluid spreads increasingly onto the sample surface with increasing velocity according to Glauert [19], [20] description of the wall jet. However, because of the horizontal configuration of the jet and the lateral aspiration of the peristaltic pump, the diffusion layer is not cylindrically symmetric. This layer flattens out to a constant thickness $\delta$.

To assess $\delta$ evolution, one considers a conical trunk between the section of the nozzle $S_{0}$ of radius $r$ and the sample surface facing $S_{1}$ of radius $R_{1}$. If the volume of fluid coming out of the nozzle $V_{S}$ which is equivalent to the volume of the conical trunk is found at the surface $S_{1}, \delta$ and $V s$ are given by:

$$
\begin{gathered}
\delta=V_{s} / S_{1} \\
V_{s}=\pi d\left(R_{1}^{2}+r R_{1}+r^{2}\right) / 3
\end{gathered}
$$

By solving the quadratic equation in $R_{1}$ from Equation (7), $R_{1}$ and $S_{1}$ for each flow are:

$$
R_{1}=-r\left(1-\sqrt{1-4\left(1-\left(3 V_{s} / \pi d r\right)\right)}\right) / 2 r
$$
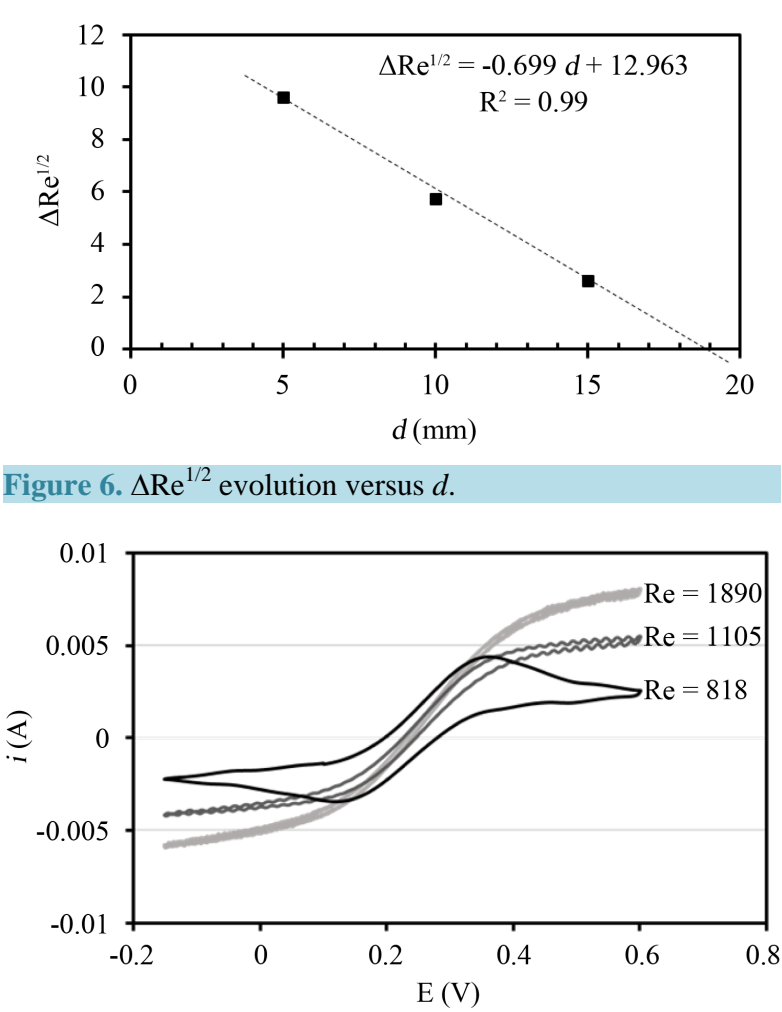

Figure 7. Cyclic voltammograms of the ferri-and ferrocyanide redox couple for various Re on steel XC 100. The counter electrode is a nickel plate. Scan rate $100 \mathrm{mV} / \mathrm{sec}, \mathrm{T}=25^{\circ} \mathrm{C}$. 


$$
S_{1}=\pi \mathrm{R}_{1}^{2}
$$

For one face of the cathode, the graph of the change of $\delta$ as a function of the half of the limiting current of oxidation $i_{\lim , O x}^{\prime}$ recorded for $d$ equal to $5 \mathrm{~mm}$ is plotted in Figure 8 .

The thickness of the diffusion layer decreases as $i_{\lim , O x}^{\prime}$ increases. The contraction of the diffusion layer enhances the mass transport and so the limiting current. The flattening of $\delta$ may result in a larger flow area when the flow rate increases. Considering both jets reach the electrode surface into laminar and the lateral peristaltic aspiration, the flow may define an ovoid plan that merges with the plan of the sample. Since the electrolyte aspiration velocity and the incident jets flow rate are the same, the stability in this hydrodynamic plan including the sample is guaranteed. A sketch of this plan in showed in Figure 9.

\section{Conclusions}

This study has consisted in the design and hydrodynamic characterization of a horizontal electrochemical impinging jet cell. The flows on the working electrode have been successfully mapped using the silica particles imprint in the nickel coating. Thus, the stagnation area, the radial flow area, the return flow area and the homogeneous drainage flow area have been characterized. The amount of embedded particles is the highest in stagnation area.

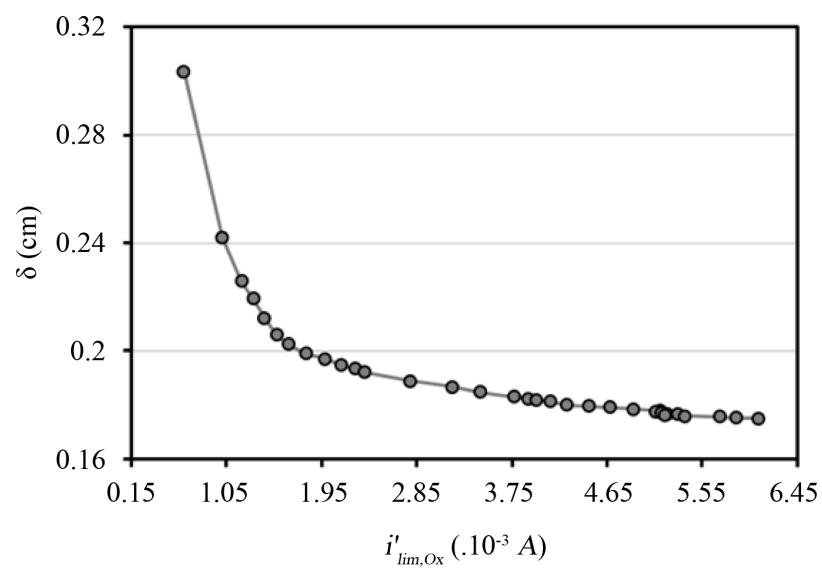

Figure 8. Evolution of the thickness $\delta$ as a function of limiting current of oxidation, $d=5 \mathrm{~mm}$.

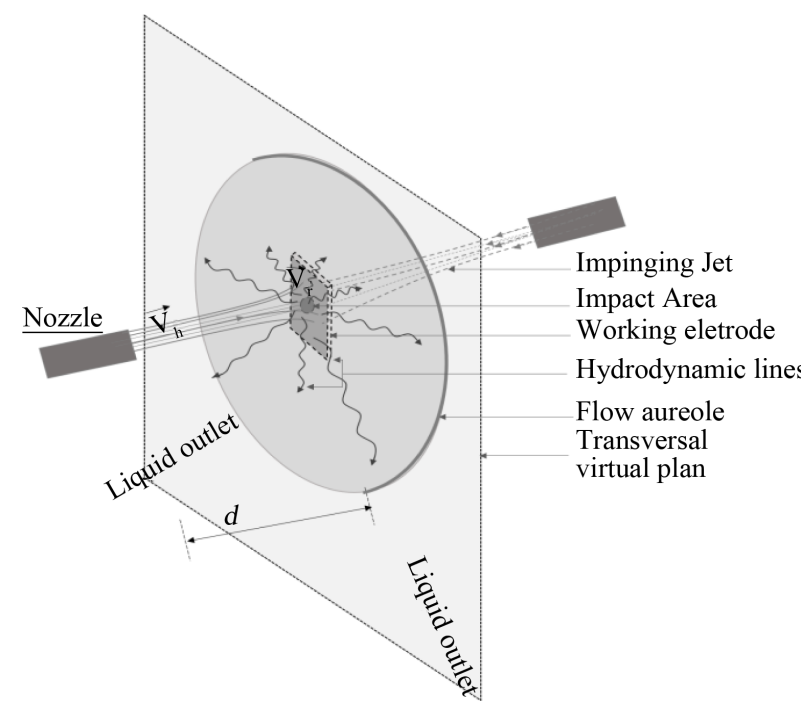

Figure 9. Ovoid plan of laminar flow confounded with the plan of the sheet. 
The change of the limiting current as a function of the square root of Reynolds number has allowed to identify three flow regimes namely the laminar low flow, the laminar high flow separated by a disturbance region. The impinging jet cell developed is capable to ensure a laminar regime regardless of the flow from a nozzle-tocathode distance estimated at $19 \mathrm{~mm}$. Based on the evolution of the diffusion layer thickness, the existence of a hydrodynamic ovoid plan merged with the working electrode has been considered.

\section{Acknowledgements}

The authors are grateful to the Swiss Government for their support through the "Swiss Government Excellence Scholarship" (No. 2012.067/Côte d'Ivoire/OP).

\section{References}

[1] Croussier, J., Eyraud, M., Croussier, J.-P. and Roman, J.-M. (1992) Influence of Substrate on the Electrode Position of Nickel-Molybdenum Alloys. Journal of Applied Electrochemistry, 22, 749-755. http://dx.doi.org/10.1007/BF01027505

[2] Yeh, S.H. and Wan, C.C. (1994) Codeposition of SiC Powders with Nickel in a Watts Bath. Journal of Applied Electrochemistry, 24, 993-1000. http://dx.doi.org/10.1007/BF00241190

[3] Losiewicz, B., Stepien, A., Gierlot, D. and Budniok, A. (1999) Composite Layers in Ni-P System Containing TiO $\mathrm{T}_{2}$ and PTFE. Thin Solid Films, 349, 43-50. http://dx.doi.org/10.1016/S0040-6090(99)00175-3

[4] Li, J., Sun, Y., Sun, X. and Qiao, J. (2005) Mechanical and Corrosion-Resistance Performance of Electrodeposited Titania-Nickel Nanocomposite Coatings. Surface and Coatings Technology, 192, 331-335. http://dx.doi.org/10.1016/j.surfcoat.2004.04.082

[5] Özkan, S., Hapçı, G., Orhan, G. and Kazmanlı, K. (2013) Electrodeposited Ni/SiC Nanocomposite Coatings and Evaluation of Wear and Corrosion Properties. Surface and Coatings Technology, 232, 734-741. http://dx.doi.org/10.1016/j.surfcoat.2013.06.089

[6] Fink, C.G. and Prince, J.D. (1928) Codeposition of Copper and Graphite. Transactions of the American Electrochemical Society, 54, 315, 1928.

[7] Ger, M.-D. (2004) Electrochemical Deposition of Nickel/SiC Composites in the Presence of Surfactants. Materials Chemistry and Physics, 87, 67-74. http://dx.doi.org/10.1016/j.matchemphys.2004.04.022

[8] Thiemig, D., Bund, A. and Talbot, J.B. (2007) Electrocodeposition of Nickel Nanocomposites Using an Impinging Jet Electrode. Journal of the Electrochemical Society, 154, D510-D515. http://dx.doi.org/10.1149/1.2767415

[9] Dablé, P.J.M.R., Chaïnet, E., Yao, B. and Gossan, A. (2009) Conceiving of an Electrochemical Cell for In Situ Hydrodynamic Approach. The Open Chemical Engineering Journal, 3, 1-7. http://dx.doi.org/10.2174/1874123100903010001

[10] Stappers, L. and Fransaer, J. (2005) The Effect of Turbulence on the Electrodeposition of Composite Coatings. Journal of the Electrochemical Society, 152, C392. http://dx.doi.org/10.1149/1.1914745

[11] Low, C.T.J., Wills, R.G.A. and Walsh, F.C. (2006) Electrodeposition of Composite Coatings Containing Nanoparticles in a Metal Deposit. Surface and Coatings Technology, 201, 371-383. http://dx.doi.org/10.1016/j.surfcoat.2005.11.123

[12] Vaezi, M.R., Sadrnezhaad, S.K. and Nikzad, L. (2008) Electrodeposition of Ni-SiC Nano-Composite Coatings and Evaluation of Wear and Corrosion Resistance and Electroplating Characteristics. Colloids and Surfaces A: Physicochemical and Engineering Aspects, 315, 178. http://dx.doi.org/10.1016/j.colsurfa.2007.07.027

[13] Yao, Y., Yao, S., Zhang, L. and Wang, H. (2007) Electrodeposition and Mechanical and Corrosion Resistance Properties of Ni-W/SiC Nanocomposite Coatings. Materials Letters, 61, 68. http://dx.doi.org/10.1016/j.matlet.2006.04.007

[14] Chin D.-T. and Hsueh, K.-L. (1986) An Analysis Using the Chilton-Colburn Analogy for Mass Transfer to a Flat Surface from an Unsubmerged Impinging Jet. Electrochimica Acta, 31, 561-564. http://dx.doi.org/10.1016/0013-4686(86)85033-2

[15] Osborne, S.J., Sweet, W.S., Vecchio, K.S. and Talbot, J.B. (2007) Electroplating of Copper-Alumina Nanocomposite Films with an Impinging Jet Electrode. Journal of the Electrochemical Society, 154, D394. http://dx.doi.org/10.1149/1.2744139

[16] Bouet, V., Gabrielli, C., Maurin, G. and Takenouti, H. (1992) Application of Electrochemical Impedance Analysis to the Characterization of Mass Transfer in a Submerged Impinging Jet Cell. Journal of Electroanalytical Chemistry, 340,325-331. http://dx.doi.org/10.1016/0022-0728(92)80307-P

[17] Coeuret, F. and Stork, A. (1993) Eléments de génie électrochimique. Techniques et Documentation, Lavoisier, Paris.

[18] Dablé, P.J.M.R. and Abro, D.M.K. (In Press) Surface Coating by Ni and Ni/Si Co-Deposition for Carbonaceous Steel Burners Protection from Corrosion at High Temperature. Engineering, Technology \& Applied Science Research. 
[19] Glauert, M.B. (1956) The Wall Jet. Journal of Fluid Mechanics, 1, 625-643. http://dx.doi.org/10.1017/S002211205600041X

[20] Yamada, J. and Matsuda, H. (1973) Limiting Diffusion Currents in Hydrodynamic Voltammetry. III. Wall Jet Electrodes. Journal of Electroanalytical Chemistry and Interfacial Electrochemistry, 44, 89-198.

http://dx.doi.org/10.1016/s0022-0728(73)80245-1

\section{Submit or recommend next manuscript to SCIRP and we will provide best service for you:}

Accepting pre-submission inquiries through Email, Facebook, LinkedIn, Twitter, etc.

A wide selection of journals (inclusive of 9 subjects, more than 200 journals)

Providing 24-hour high-quality service

User-friendly online submission system

Fair and swift peer-review system

Efficient typesetting and proofreading procedure

Display of the result of downloads and visits, as well as the number of cited articles

Maximum dissemination of your research work

Submit your manuscript at: http://papersubmission.scirp.org/ 